\title{
Florística, Fitossociologia e Índices de Diversidade da Caatinga em Assentamento Rural no Rio Grande do Norte, Brasil
}

\author{
José Augusto da Silva Santana ${ }^{1}$, Adriana Figueredo da Silva Zaccharias ${ }^{1}$, Amanda Brito da Silva ${ }^{1}$, \\ Ageu da Silva Monteiro Freire ${ }^{1} \&$ Eduardo Garcia Zaccharias ${ }^{1}$
}

Recebido em 09/11/2020 - Aceito em 05/02/2021

1 Laboratório de Ecologia Florestal, Universidade Federal do Rio Grande do Norte/UFRN, Campus de Macaiba/RN. Brasil. < augusto@ufrnet.br, adriana.figueredos@gmail.com, amandabfloresta@gmail.com, ageufreire@hotmail.com,eduardogarciazaccharias@gmail.com>.

\begin{abstract}
RESUMO - A Caatinga é um bioma localizado na região Nordeste do Brasil, abrangendo cerca de $10 \%$ do território nacional e com elevada população dependente dos produtos oriundos de sua vegetação. O objetivo deste trabalho foi caracterizar a composição florística, fitossociológica e a diversidade do componente arbóreo-arbustivo na área dos lotes do Assentamento Rural Lagoa Nova I, localizado no município de Riachuelo, Rio Grande do Norte/RN. Para tanto, realizou-se o levantamento florístico em 15 unidades amostrais de $20 \times 10 \mathrm{~m}\left(200 \mathrm{~m}^{2}\right)$, onde, em cada unidade amostral, foram inventariados todos os indivíduos arbóreo-arbustivos vivos que apresentaram circunferência a $1,30 \mathrm{~m}$ do solo superior ou igual a $15 \mathrm{~cm}(\mathrm{CAP} \geq 15 \mathrm{~cm})$. Avaliaram-se os parâmetros fitossociológicos e a estrutura, além da diversidade florística das espécies através do Índice de Shannon-Weaver, a dominância de Simpson e a equabilidade de Pielou. Depois de mais de 30 anos após a erradicação do cultivo de algodão na área, com a vegetação dos lotes sendo mantida em sistema de pousio, observou-se que a família com maior destaque foi a Fabaceae, com 8 espécies e 186 indivíduos, enquanto as espécies com maior importância na área de estudo foram Poincianella pyramidalis (15,55\%), Bumelia sartorum (12,46\%) e Mimosa tenuiflora (11,25\%). A diversidade de espécies na área dos lotes dos assentados foi considerada acima da média, quando comparada com outros fragmentos florestais de Caatinga já estudados, com condições edafoclimáticas semelhantes, e se encontra em bom estado de preservação, estando ainda no estágio inicial de sucessão ecológica.
\end{abstract}

Palavras-chave: Lagoa Nova I; vegetação; estrutura horizontal.

\section{Floristic, Phytosociology and Diversity Indexes of the Caatinga in Rural Settlement in the Rio Grande do Norte, Brazil}

ABSTRACT - The Caatinga is a biome located in the Northeast region of Brazil covering about $10 \%$ of the national territory and with a high population dependent on products from its vegetation. The objective of this work was to characterize the diversity, the floristic composition and the phytosociology of the tree-shrub component in the area of the lots in the Lagoa Nova I Rural Settlement, located in the municipality of Riachuelo, Rio Grande do Norte/RN. For this purpose, a floristic survey was carried out in 15 sampling units of $20 \times 10 \mathrm{~m}\left(200 \mathrm{~m}^{2}\right)$, where in each sampling unit, all live tree-shrub forest individuals who had a breast height circumference greater than or equal to $15 \mathrm{~cm}$ (CAP $\geq$ $15 \mathrm{~cm}$ ) were inventoried and the phytosociological parameters and structure were evaluated, as well as the floristic diversity of the species through the Shannon-Weaver Index, Simpson's dominance and Pielou's equability. After more than 30 years after the eradication of cotton cultivation in the area, with the vegetation of the lots being maintained in fallow system, it was observed that the most prominent family was Fabaceae, with 8 species and 186 individuals, while the species with greater importance in the study area were Poincianella pyramidalis (15.55\%), Bumelia sartorum (12.46\%) and Mimosa tenuiflora (11.25\%). The diversity of species in the area of the lots was considered above average when compared to other forest fragments of Caatinga already studied, with similar edaphoclimatic conditions, and is in a good state of preservation, still in the initial stage of ecological succession.

Keywords: Lagoa Nova I; vegetation; horizontal structure. 


\title{
Florística, Fitosociología e Índices de Diversidad de la Caatinga en Asentamiento Rural en Rio Grande do Norte, Brasil
}

\begin{abstract}
RESUMEN - La Caatinga es un bioma ubicado en la región Nordeste de Brasil, que cubre alrededor del $10 \%$ del territorio nacional y con una alta población dependiente de los productos derivados de su vegetación. El objetivo de este trabajo fue caracterizar la composición florística, fitosociológica y la diversidad del componente árbol-arbusto en la zona de los lotes del Asentamiento Rural Lagoa Nova I, ubicado en el municipio de Riachuelo, Rio Grande do Norte/RN. Para ello, el estudio florístico se llevó a cabo en 15 unidades de muestra de $20 \times 10 \mathrm{~m}\left(200 \mathrm{~m}^{2}\right)$, donde se inventariaron todos los individuos vivos árbol-arbusto que presentaran circunferencia a $1,30 \mathrm{~m}$ del suelo superior o igual a $15 \mathrm{~cm}$ (CAP $\geq 15 \mathrm{~cm}$ ). Se evaluaron los parámetros fitosociológicos y la estructura, así como la diversidad florística de la especie utilizando el índice de Shannon-Weaver, la dominancia de Simpson y la igualdad de Pielou. Después de más de 30 años de la erradicación del cultivo del algodón en la zona, con la vegetación de los lotes mantenida en sistema de pousio, se observó que la familia más destacada fue Fabaceae, con 8 especies y 186 individuos, mientras que las especies con mayor importancia en el área de estudio fueron Poincianella pyramidalis (15,55\%), Bumelia sartorum $(12,46 \%)$ y Mimosa tenuiflora (11,25\%). La diversidad de especies en el área de los lotes de los colonos se consideró por encima del promedio cuando se compara con otros fragmentos de bosque de Caatinga ya estudiados, con condiciones edafoclimáticas similares, y se encuentra en buenas condiciones de conservación, aún en la etapa inicial de sucesión ecológica.
\end{abstract}

Palabras clave: Lagoa Nova I; vegetación; estructura horizontal.

\section{Introdução}

Apesar da significativa extensão, da importância socioeconômica e de ocupar significativa área no território nacional, a Caatinga é o menos protegido dentre os biomas brasileiros, e, de acordo com Oliveira et al. (2019), possui apenas 7,7\% de sua área destinada a conservação, sendo que mais de $80 \%$ dessa área conservada está na categoria de uso sustentável, necessitando assim de expansão na quantidade de unidades de conservação (UCs). Além da reduzida área sob proteção e das restritivas condições climáticas, o impacto da atividade humana sobre o bioma é descontrolado, danoso e considerável, aumentando os níveis de degradação do bioma (Alves et al., 2017).

De acordo com Medeiros Neto et al. (2014), a Caatinga vem sendo explorada intensivamente de maneira inadequada, para finalidades energéticas e construções rurais (cercas, currais $e$ telhados), contribuindo para a escassez da madeira de algumas espécies nativas e para a degradação da Caatinga devido à retirada de madeira em grande quantidade. Ou seja, os desmatamentos, especialmente para fins energéticos e agrícolas, são os maiores responsáveis pela modificação do bioma Caatinga, podendo implicar na desertificação, processo de degradação ambiental que ocorre em áreas áridas, semiáridas $e$ subsumidas secas (Sá et al., 2010).
Machado \& Lopes (2003) destacam que, apesar da grande extensão e considerando a importância da Caatinga para o nordeste do Brasil, pouca são ainda as informações ecológicas sobre esse bioma, havendo carência de publicações enfocando a biologia e a dinâmica das espécies, entre outros assuntos relevantes.

Assim, considera-se que há necessidade de uma política efetiva para a conservação do bioma, tendo em vista a manutenção do seu alto grau de endemismo e riqueza de espécies (Queiroz, 2009), pois, ao longo do processo de uso e ocupação do espaço semiárido, o mesmo vêm passando por intensos processos de degradação devido às práticas agropecuárias e ao extrativismo vegetal, realizados de forma intensiva, e em muitos casos, de forma predatória, resultando na perda da cobertura vegetal (Nascimento et al., 2014).

Apesar da intensa degradação, as comunidades residentes na região do bioma apresentam elevada dependência dos recursos oriundos da floresta, os quais são essenciais para sustentação e manutenção das comunidades (Maia, 2012), principalmente na fase inicial de instalação dos assentamentos rurais quando há maior necessidade de madeira e produtos da floresta.

De acordo com Miranda (2003), apesar de se ter aumentado a preocupação com a conservação da Caatinga, ainda é muito intensa a pressão sobre 
os remanescentes, tanto por parte da expansão da agropecuária, quanto pela exploração dos produtos florestais que visa atender às demandas do mercado.

Com isso são fundamentais os estudos da dinâmica ecológica da vegetação de Caatinga, principalmente de parâmetros florísticos, fitossociológicos e sucessionais, pois propiciam informações relevantes para orientar a recuperação das áreas degradadas pela exploração irracional de recursos naturais (Leite, 1999).

Além disso, estudos que proponham a identificação e a conservação das espécies da Caatinga são essenciais, e o conhecimento da composição florística e da estrutura da vegetação possibilita uma base para a tomada de decisões em relação aos métodos e técnicas adequadas em ações futuras de manejo (Araújo, 2007).
Diante disso o presente trabalho teve como objetivo avaliar a composição florística, a diversidade e os parâmetros fitossociológicos da vegetação arbustivo-arbórea de uma área de Caatinga ocorrente nos lotes dos assentados do Assentamento Rural Lagoa Nova I, no município de Riachuelo, Rio Grande do Norte/RN.

\section{Material e Métodos}

O estudo foi desenvolvido no Assentamento Rural Lagoa Nova I, localizado no município de Riachuelo, no estado do Rio Grande do Norte (Figura 1), o qual possui 7.234,18 hectares, sendo localizado nas coordenadas centrais: $5^{\circ} 48^{\prime} 54^{\prime \prime} \mathrm{S}$ e 35 49' 30" W, estando a uma altitude média de $118 \mathrm{~m}$, distando $75 \mathrm{~km}$ de Natal, capital do estado. A área foi desapropriada em janeiro de 1998, sendo efetivamente criado o Assentamento em março do mesmo ano para assentar 240 famílias.

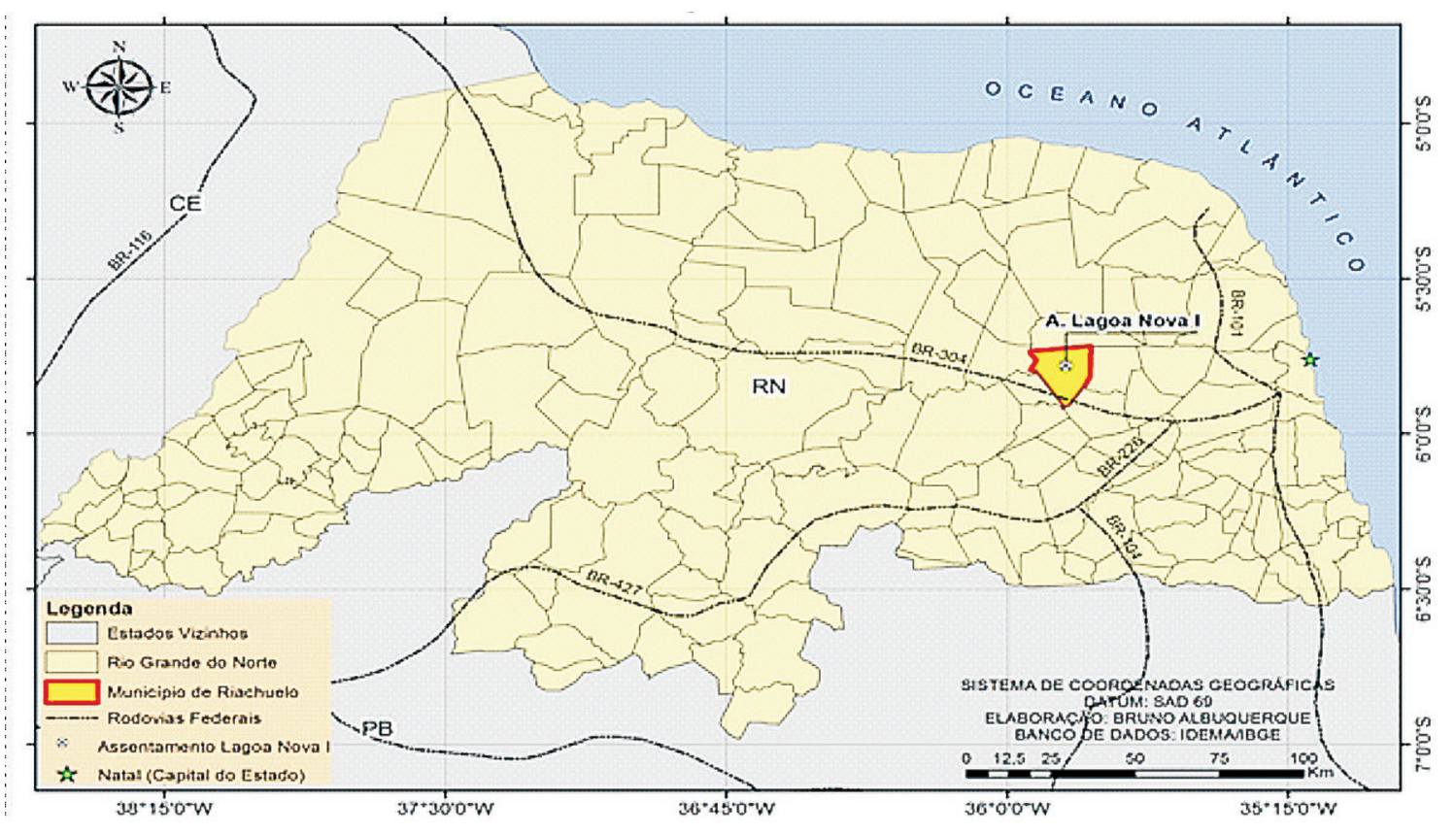

Figura 1 - Mapa do estado do Rio Grande do Norte com a localização do Projeto de Assentamento Lagoa Nova I, no município de Riachuelo/RN.

De acordo com a classificação de Köppen, o clima da região é classificado como Bsh tratandose de clima semiárido, sendo a precipitação inferior a evaporação. Os valores referentes às chuvas demonstram que a pluviosidade entre os anos é variável, com a média total anual atingindo
$619,55 \mathrm{~mm}$, e o período chuvoso se estendendo de março a julho, enquanto que no trimestre outubro-dezembro ocorre o período mais seco do ano (Figura 2). Além disso, a temperatura atinge a média anual de $27,2^{\circ} \mathrm{C}$, e a umidade relativa média anual chega a 70\% (Climate-Data, 2016). 


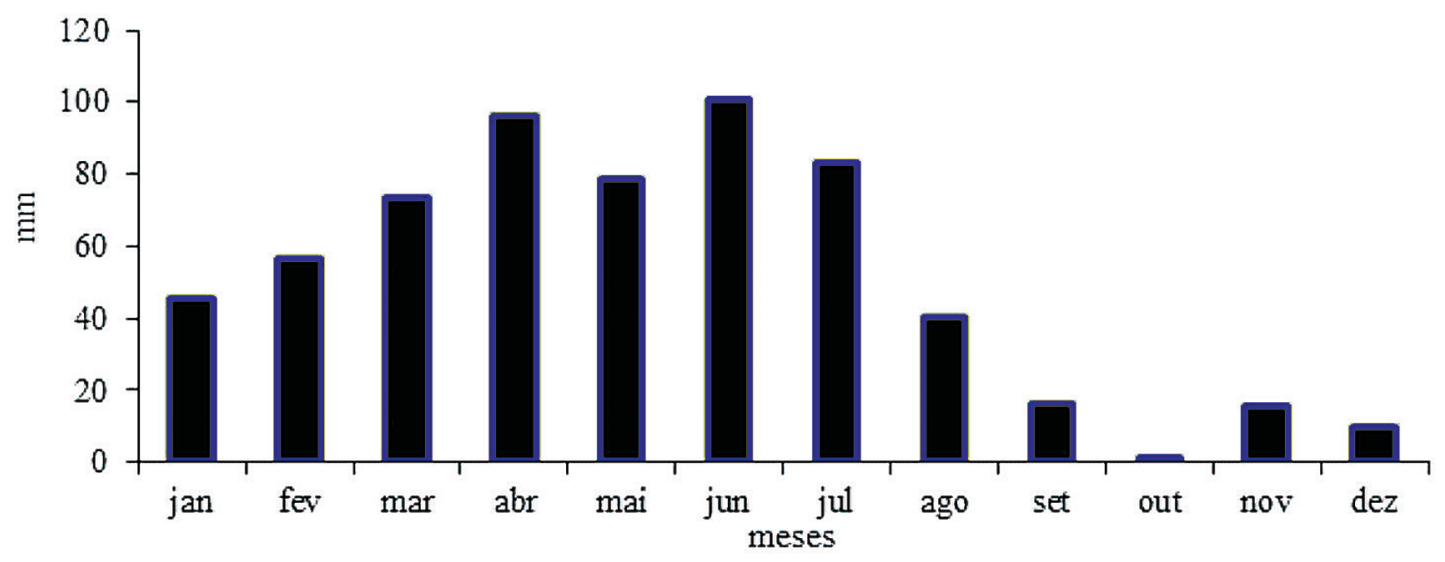

Figura 2 - Distribuição média mensal de precipitação no município de Riachuelo/RN, no período de 2006-2016.

O município situa-se em área de domínio do Embasamento Cristalino, e o solo tem características predominantes de Planossolo Solódico com boa fertilidade natural, textura argilosa e pouco arenosa, relevo plano a suave ondulado e bem drenado, com alguma pedregosidade no perfil (Embrapa, 2014).

A vegetação das parcelas é considerada como secundária, visto que anteriormente as áreas dos lotes foram exploradas com atividades agrícolas, principalmente plantio de algodão, estando em pousio há mais de 30 anos, não apresentando sinais intensos de ação antrópica. Há predominância de Poincianella pyramidalis Tul., Bumelia sartorum Mart., Piptadenia stipulacea (Benth.) Ducke e Croton sonderianus Muell. Arg., além de cactáceas como Cereus jamacaru D.C. e Pilosocereus pachycladus Ritter.

Para realizar o levantamento da vegetação foi utilizado o método das parcelas múltiplas, com 15 parcelas retangulares medindo $20 \mathrm{~m}$ x $10 \mathrm{~m}$, escolhidas aleatoriamente. De acordo com Martins (1991), essa metodologia em estudos fitossociológicos permite avaliar de forma quantitativa a variabilidade dos parâmetros estudados e pode, também, fornecer informações seguras quanto ao padrão espacial de distribuição dos indivíduos em cada população.

O inventário florístico incluiu todas as plantas vivas em cada parcela com circunferência à altura do peito (CAP) superior ou igual a $15 \mathrm{~cm}$, sendo todas identificadas e medidas suas alturas com auxílio de régua graduada em centímetros. A identificação botânica foi realizada inicialmente no campo e, quando necessário, foram feitas consultas ao Herbário da Universidade Federal do Rio Grande do Norte, através de amostras botânicas de material fértil, com os quais foram confeccionadas exsicatas. A lista florística gerada foi organizada de acordo com sistema de classificação APG IV (2016).

A diversidade florística e a abundância relativa das espécies foram analisadas utilizando o índice de diversidade de Shannon-Weaver $\left(\mathrm{H}^{\prime}\right)$ (Magurran, 1988), de dominância de Simpson (C) e de equabilidade de Pielou (J) (Brower \& Zar, 1984), enquanto que a caracterização da estrutura horizontal da comunidade arbustivoarbórea foi estimada por meio dos parâmetros fitossociológicos da frequência, densidade, dominância e dos índices de valor de importância de cada espécie amostrada. Os cálculos dos parâmetros fitossociológicos e das estimativas dos índices foram realizados utilizando-se o aplicativo Excel.

Na análise da distribuição diamétrica foram empregadas amplitudes de classe com $3 \mathrm{~cm}$, enquanto que a caracterização da estrutura vertical foi analisada por meio da distribuição em classes de altura com amplitudes de $1,0 \mathrm{~m}$.

\section{Resultados e Discussão}

Nas 15 parcelas inventariadas foram amostrados 397 indivíduos, representados por 24 espécies, 24 gêneros e 13 famílias (Tabela 1), com densidade média de 1.323 indivíduos ha ${ }^{-1}$, sendo 79,2\% das espécies de porte arbóreo. 
Tabela 1 - Espécies inventariadas, em ordem alfabética de família, em lotes do Assentamento Rural Lagoa Nova I, Riachuelo/RN, com nome comum e hábito.

\begin{tabular}{|c|c|c|}
\hline Família/Espécie & Nome comum & Hábito \\
\hline \multicolumn{3}{|l|}{ Anacardiaceae } \\
\hline Myracrodruon urundeuva M. Allemão & Aroeira & Árvore \\
\hline Spondias tuberosa Arruda & Umbuzeiro & Árvore \\
\hline \multicolumn{3}{|l|}{ Apocynaceae } \\
\hline Aspidosperma pyrifolium Mart. & Pereiro & Árvore \\
\hline \multicolumn{3}{|l|}{ Burseraceae } \\
\hline Commiphora leptophloeos (Mart.) Gillet & Imburana & Árvore \\
\hline \multicolumn{3}{|l|}{ Cactaceae } \\
\hline Cereus jamacaru DC. & Mandacaru & Arbusto \\
\hline Pilosocereus pachycladus Ritter. & Facheiro & Arbusto \\
\hline \multicolumn{3}{|l|}{ Caparaceae } \\
\hline Capparis flexuosa Linn. & Feijão bravo & Arbusto \\
\hline \multicolumn{3}{|l|}{ Combretaceae } \\
\hline Combretum leprosum Mart. & Mofumbo & Arbusto \\
\hline \multicolumn{3}{|l|}{ Euphorbiaceae } \\
\hline Sapium lanceolatum (Müll. Arger.) Huber. & Burra Leiteira & Árvore \\
\hline Manihot glaziovi Müll. Arg. & Maniçoba & Árvore \\
\hline Croton sonderianus Müll. Arg. & Marmeleiro & Arbusto \\
\hline \multicolumn{3}{|l|}{ Fabaceae } \\
\hline Poincianella pyramidalis (Tul.) L.P. Queiroz & Catingueira & Árvore \\
\hline Anadenanthera macrocarpa (Benth.) Brenan & Angico & Árvore \\
\hline Bauhinia cheilantha (Bong.) Stand. & Mororó & Árvore \\
\hline Libidibia ferrea (Mart. ex Tul.) L.P. Queiroz & Jucá & Árvore \\
\hline Mimosa tenuiflora (Willd.) Poir. & Jurema Preta & Árvore \\
\hline Piptadenia stipulacea (Benth.) Ducke & Jurema Branca & Árvore \\
\hline Amburana cearensis Allemão & Cumaru & Árvore \\
\hline Mimosa arenosa (Willd.) Poir. & Espinheiro & Árvore \\
\hline \multicolumn{3}{|l|}{ Malvaceae } \\
\hline Helicteres mollis K. Schum & Guaxuma & Árvore \\
\hline \multicolumn{3}{|l|}{ Nictaginaceae } \\
\hline Guapira oppositifolia Vell. & João Mole & Árvore \\
\hline \multicolumn{3}{|l|}{ Olacaceae } \\
\hline Ximenia americana L. & Ameixa & Árvore \\
\hline \multicolumn{3}{|l|}{ Rhamnaceae } \\
\hline Ziziphus joazeiro Mart. & Juazeiro & Árvore \\
\hline \multicolumn{3}{|l|}{ Sapotaceae } \\
\hline Bumelia sartorum Mart. & Quixabeira & Árvore \\
\hline
\end{tabular}


Esse valor de densidade evidencia que a vegetação estudada pode ser considerada como mediana em termos de número de indivíduos, $e$ dentro das variações em níveis florísticos observados nas diferentes tipologias da Caatinga, visto que Marangon et al. (2013) registraram 18 espécies arbóreas em uma área com histórico de perturbação e 1.227 indivíduos ha-1 ${ }^{-1}$ enquanto Silva (2009) em estudo de Caatinga com histórico de diferentes usos no agreste pernambucano, encontrou 34 espécies na área I e 29 na II, com densidades de 3.860 e 1.993 indivíduos ha-1, respectivamente, e Guedes (2010) notificou a presença de 21 espécies e 1.666 indivíduos ha-1. $^{-1}$.

As famílias Fabaceae com oito espécies, Euphorbiaceae com três espécies, e Anacardiaceae e Cactaceae com duas espécies cada, apresentaram maior riqueza de espécies, representando $62,5 \%$ das espécies ocorrentes nos lotes, ratificando o que outros autores como Santana et al. (2009), Santos et al. (2011), Guedes et al. (2012) e Farias et al. (2017) constataram em estudos semelhantes no bioma, assim como Araújo (2007), em uma área de reserva particular do patrimônio natural (RPPN) na Fazenda Tamanduá, no município de Santa Terezinha, estado da Paraíba, a qual não sofria ação antrópica há pelo menos trinta anos, onde foram identificadas 27 espécies de 15 famílias botânicas.

Conforme Giulietti et al. (2002) citam, as espécies: Spondias tuberosa, Aspidosperma pyrifolium, Commiphora leptophloeos, Cereus jamacaru, Pilosocereus pachycladus, Capparis flexuosa, Manihotglaziovi, Poincianella pyramidalis e Ziziphus joazeiro são consideradas endêmicas do bioma Caatinga e representam 37,5\% do total de espécies inventariadas na área.

As espécies que apresentaram os maiores número de indivíduos na área estudada foram Poincianella pyramidalis, Bumelia sartorum, Mimosa tenuiflora, Piptadenia stipulacea e Aspidosperma pyrifolium totalizando $64 \%$ dos indivíduos inventariados (Tabela 2).

Poincianella pyramidalis foi a espécie de maior destaque na população vegetal estudada, apresentando o maior número de indivíduos (81) $e$, consequentemente, o maior valor de densidade relativa e também a maior frequência relativa, ocorrendo em $80 \%$ das parcelas. Além disso, obteve o terceiro maior valor de dominância relativa, tornando-se, assim, a espécie com maior $\mathrm{VI}$ e VC na vegetação dos lotes.
É uma das espécies mais presentes nos levantamentos já realizados no bioma Caatinga, aparecendo em vários locais, normalmente com número significativo de representantes, porém raramente ocorre com altura e diâmetros médios acentuados (Santana \& Souto, 2006; Rodal et al., 2008), tendo já sido registrada nos estados do Piauí, Ceará, Rio Grande do Norte, Paraíba, Pernambuco, Alagoas, Sergipe e Bahia, sendo considerada endêmica da Caatinga (Giulietti et al., 2002).

É também uma das espécies da Caatinga mais exploradas pela população local como fonte de lenha e carvão vegetal, para fins medicinais e também forrageiros. Aurino (2007) considera que, apesar do crescimento relativamente pequeno no estádio inicial, a espécie possui grande resistência à seca e boa capacidade de competição por luz, tornando-se uma das espécies dominantes nas etapas posteriores do processo de regeneração.

Outra espécie que se destacou no inventário florístico foi Bumelia sartorum, sendo a segunda espécie com maior ocorrência na área dos lotes, densidade relativa, dominância relativa, valor de cobertura e valor de importância. Pertencente à família Sapotaceae apresenta ampla distribuição geográfica, ocorrendo desde parte da América Central à América do Sul. No Brasil ocorre em todas as regiões (Carneiro et al., 2015) e nos biomas Caatinga, Cerrado, Mata Atlântica, Pantanal, apresentando grande concentração de indivíduos no nordeste do Brasil, sendo considerada como clímax por Scipioni et al. (2013), indicando ser mais tolerante ao sombreamento.

Bumelia sartorum pode ser considerada como uma espécie multiuso, já que tem sido utilizada em projetos de arborização urbana (Dantas \& Souza, 2004) e de recuperação de mata ciliar (Ribeiro-Filho et al., 2009), além do uso de sua madeira na construção civil, artesanal e produção de lenha. Sua casca tem propriedades terapêuticas, o que tem provocado a escassez da mesma no semiárido nordestino (Alves et al., 2008), tornando-a sensível ao desaparecimento, e por isso é prioritária para a conservação (Melo et al., 2009). Para agravar ainda mais o problema da espécie, a predação por caprinos tanto na fase adulta como na fase de plântula, torna-a uma planta vulnerável em áreas de caprinocultura extensiva, conforme comentam Leal et al. (2007). 


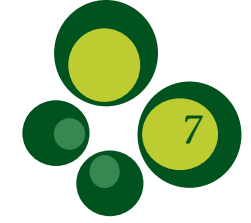

Tabela 2 - Parâmetros fitossociológicos das espécies ocorrentes em lotes do Assentamento Rural Lagoa Nova I, Riachuelo/RN, relacionadas por ordem decrescente do valor de importância.

\begin{tabular}{|c|c|c|c|c|c|c|}
\hline \multirow{2}{*}{ Espécies } & \multirow{2}{*}{ NI } & DeR & FrR & DoR & VI & VC \\
\hline & & \multicolumn{5}{|c|}{ 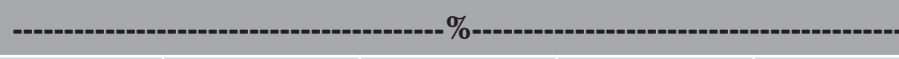 } \\
\hline Poincianella pyramidalis & 81 & 20,40 & 10,81 & 15,45 & 15,55 & 17,93 \\
\hline Bumelia sartorum & 56 & 14,11 & 5,41 & 17,88 & 12,46 & 16,00 \\
\hline Mimosa tenuiflora & 46 & 11,59 & 6,31 & 15,87 & 11,25 & 13,73 \\
\hline Pilosocereus pachycladus & 27 & 6,80 & 9,91 & 9,57 & 8,76 & 8,19 \\
\hline Aspidosperma pyrifolium & 35 & 8,82 & 8,11 & 6,20 & 7,71 & 7,51 \\
\hline Piptadenia stipulacea & 36 & 9,07 & 9,01 & 4,40 & 7,49 & 6,74 \\
\hline Guapira oppositifolia & 21 & 5,29 & 5,41 & 7,87 & 6,19 & 6,58 \\
\hline Sapion lanceolatum & 17 & 4,28 & 6,31 & 2,27 & 4,29 & 3,28 \\
\hline Helicteres mollis & 15 & 3,78 & 6,31 & 2,03 & 4,04 & 2,91 \\
\hline Ziziphus joazeiro & 11 & 2,77 & 5,41 & 2,40 & 3,53 & 2,59 \\
\hline Bauhinia cheilantha & 14 & 3,53 & 3,60 & 1,94 & 3,02 & 2,74 \\
\hline Anadenanthera macrocarpa & 6 & 1,51 & 3,60 & 2,95 & 2,69 & 2,23 \\
\hline Cereus jamacaru & 7 & 1,76 & 3,60 & 2,28 & 2,55 & 2,02 \\
\hline Commiphora leptophloeos & 3 & 0,76 & 2,70 & 3,10 & 2,19 & 1,93 \\
\hline Myracrodruon urundeuva & 4 & 1,01 & 2,70 & 1,98 & 1,90 & 1,50 \\
\hline Manihot glaziovii & 6 & 1,51 & 1,80 & 1,29 & 1,53 & 1,40 \\
\hline Croton sonderianus & 4 & 1,01 & 1,80 & 0,47 & 1,09 & 0,74 \\
\hline Spondias tuberosa & 2 & 0,50 & 1,80 & 0,89 & 1,06 & 0,70 \\
\hline Amburana cearensis & 1 & 0,25 & 0,90 & 0,42 & 0,53 & 0,34 \\
\hline Capparis flexuosa & 1 & 0,25 & 0,90 & 0,26 & 0,47 & 0,26 \\
\hline Libidibia férrea & 1 & 0,25 & 0,90 & 0,20 & 0,45 & 0,23 \\
\hline Ximenia americana & 1 & 0,25 & 0,90 & 0,10 & 0,42 & 0,18 \\
\hline Mimosa arenosa & 1 & 0,25 & 0,90 & 0,10 & 0,42 & 0,18 \\
\hline Combretum leprosum & 1 & 0,25 & 0,90 & 0,08 & 0,41 & 0,17 \\
\hline TOTAL & 397 & 100 & 100 & 100 & 100 & 100 \\
\hline
\end{tabular}

A terceira espécie com maior valor de importância e de cobertura na área estudada e que sempre tem sido encontrada nos diversos levantamentos florísticos realizados no bioma Caatinga (Santana, 2005) é Mimosa tenuiflora, considerada uma espécie oportunista e secundária, estabelecendo-se rapidamente em áreas antropizadas, além de apresentar grande amplitude de tolerância as condições edáficas, ocorrendo tanto em solos rasos como em profundos.

Camargo-Ricalde (2000) cita que a espécie ocorre em quase todo o nordeste brasileiro, sendo encontrada também em El Salvador, Guatemala, Nicarágua, Honduras, México, Panamá, Colômbia e Venezuela, onde é usada para produzir um carvão de alto teor calorífico e ração animal, além de formar cercas vivas. Apresenta alta durabilidade e resistência, conforme informa Oliveira (2003), e por isso é muito utilizada no Assentamento Rural estudado para fornecer estacas e mourões.

As espécies Amburana cearensis, Capparis flexuosa, Libidibia ferrea, Ximenia americana, Mimosa arenosa e Combretum leprosum ocorreram com apenas um indivíduo, podendo assim se configurar como rara na população 
estudada, apesar de que a última é bastante comum na área do Assentamento e aparece em vários inventários já realizados no bioma (Lima \& Coelho, 2018; Santana \& Souto, 2006).

Como é comum em algumas áreas do bioma, observou-se a ocorrência acentuada de espécies da família Cactaceae, representada por Pilosocereus pachycladus e Cereus jamacaru, atingindo $8,6 \%$ de todos os indivíduos inventariados. Segundo Taylor (1997), as Cactaceas podem ser encontradas em diversas condições ecológicas e climáticas, desde desertos onde as chuvas são escassas, como em partes do deserto de Atacama no Chile, até ambientes úmidos de floresta tropical, e no Brasil, ocorrem 258 espécies, das quais 184 são endêmicas. No Assentamento estudado elas são pouco utilizadas, e isso tem contribuído para sua conservação e dispersão na área.

$\mathrm{O}$ índice de diversidade de ShannonWeaver ( $\left.\mathrm{H}^{\prime}\right)$ na área de estudo atingiu 2,54 nats. ind $^{-1}$, valor inferior ao obtido por Leite et al. (2015), que estudaram a vegetação lenhosa da Caatinga em Teixeira/PB, e encontraram o valor de 3,06 nats.ind ${ }^{-1}$ e ao determinado por Leitão et al. (2014), que pesquisaram uma área de ecótono entre Caatinga/Mata Atlântica, e verificaram 3,05 nats.ind ${ }^{-1}$, mas foi superior aos encontrados por Holanda et al. (2015) em remanescentes de Caatinga com diferentes históricos de perturbação em Cajazeirinhas/PB e Dantas et al. (2010) em um fragmento de Caatinga no município de Pombal/PB e semelhante ao valor verificado por Guedes et al. (2012) em fragmento de Caatinga no município de Upanema/RN, que foi também de 2,54 nats.ind ${ }^{-1}$.

Segundo Santos et al. (2017), o índice de diversidade de Shannon $\left(\mathrm{H}^{\prime}\right)$ na Caatinga, baseado na literatura, pode variar de 1-4 nats. ind $^{-1}$. Assim o valor determinado na área dos lotes do assentamento é considerado acima da média do bioma, mesmo tendo sido forte ação antrópica na área, já que até o final da década dos anos 80 foi utilizada para plantio de algodão.

$\mathrm{O}$ índice de equabilidade de Pielou (J') permite representar a uniformidade da distribuição dos indivíduos entre as espécies existentes na área, com os valores variando de 0 a 1 , e quanto maior próximo de 1 representa a máxima equabilidade. Neste estudo foi obtido o valor de 0,80 , bem superior ao quantificado por Sabino et al. (2016) que foi de 0,63 e 0,62 em dois fragmentos antropizados na região de Patos/PB e por Cabral (2014) que atingiu 0,67, na Fazenda Tamanduá, no município de Santa Terezinha/PB. Assim, considera-se que existe baixa dominância de espécies na área dos lotes do Assentamento, o que pode refletir em alta biodiversidade, mesmo considerando a ocorrência de $P$. pyramidalis em $80 \%$ das parcelas amostradas. Deve-se observar que os assentados não realizam exploração madeireira na área e mantém grande parte dos seus lotes individuais em sistema de pousio.

$\mathrm{O}$ valor estimado do índice de dominância de Simpson varia de 0 (zero) a 1 (um), sendo que para valores próximos de 1 , a diversidade é considerada maior. $\mathrm{Na}$ área dos lotes do Assentamento estudado, o índice atingiu 0,90, enquanto Mendes Junior et al. (2009), em área que sofreu corte raso há 20 anos no município de Floresta, Pernambuco/PE, determinou o valor de 0,80 e Silva (2009) quantificou em 0,73 para uma área abandonada a cerca de 30 anos no Agreste pernambucano.

Já Calixto Júnior \& Drumond (2014), em estudo realizado em duas áreas de Caatinga em Petrolina/PE, com cerca de 30 anos em processo de regeneração, calcularam em 0,97 o índice de Simpson para aquela que sofreu corte raso e 0,96 para a outra que sofreu corte seletivo $e$ foi utilizada esporadicamente como pasto para alimentação de gado bovino. Do mesmo modo, Guedes (2010), em estudo de um fragmento que manteve sua cobertura vegetal por cerca de 30 anos, na Reserva Particular do Patrimônio Natural da Fazenda Tamanduá, determinou em 0,96 o índice de Simpson.

A distribuição dos indivíduos por classes diamétricas (Figura 3) evidencia a conformação de uma curva em forma de $\mathrm{J}$ invertido e inclinada, o que demonstra a quantidade elevada de indivíduos posicionados nas menores classes de diâmetro, o que poderia indicar ausência de problemas de regeneração.

O diâmetro médio foi considerado pequeno, atingindo apenas $7,48 \mathrm{~cm}$, o que, provavelmente, é o resultado da lenta reocupação do espaço físico pelas espécies da Caatinga, após a cultura do algodão ser erradicada da área na década de 80. De acordo com Nunes et al. (2003), a grande quantidade de indivíduos pequenos e finos pode indicar a ocorrência de severas perturbações no passado recente, como o corte para diversos fins e queimadas. 


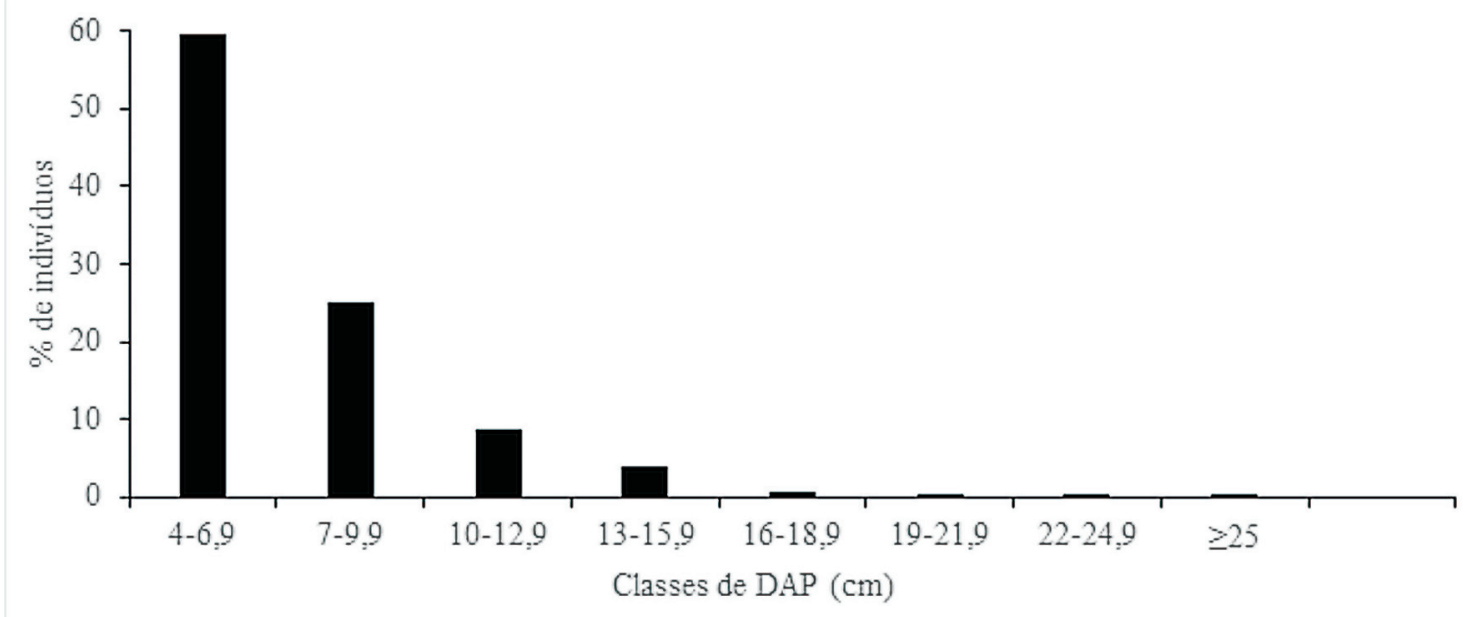

Figura 3 - Distribuição percentual dos indivíduos, em classes de DAP, na área dos lotes no Assentamento Rural Lagoa Nova I, Riachuelo/RN.

Do total de indivíduos encontrados, $84,89 \%$ se concentraram nas duas primeiras classes inferiores de diâmetro, enquanto nas três classes de maior diâmetro só foram observados seis indivíduos, o que representa cerca de $1,50 \%$ da população. As espécies que apresentaram indivíduos com DAP superior a $20 \mathrm{~cm}$ foram $G$. oppositifolia, M. tenuiflora, C. leptophloeos, B. sartorum e A. macrocarpa.

De acordo com Jesus (2010), esta forma de distribuição dos indivíduos na área tem uma grande vantagem, pois, assegura que estes irão colaborar com o processo de regeneração natural. Alcoforado-Filho et al. (2003) em um levantamento em Caruaru/PE encontraram cerca de $89 \%$ dos indivíduos com diâmetros abaixo de $12 \mathrm{~cm}$ e resultados semelhantes foram encontrados por outros autores em áreas de Caatinga (Santana \& Souto, 2006; Leite et al., 2015).

A altura da vegetação dos lotes do Assentamento variou entre $2-10 \mathrm{~m}$, com a média atingindo $5,8 \mathrm{~m}$, com destaque para dois indivíduos de Pilosocereus pachycladus que apresentaram altura de $10 \mathrm{~m}$, elevando assim a média da população inventariada. A média foi inferior ao observado por Braga; Cavalcante (2007), em fragmento de Caatinga arbórea em regeneração no Ceará, que foi de $7,73 \mathrm{~m}$, mas bem superior ao verificado por Leite et al. (2015) na Caatinga de Teixeira/PB que foi de $5,0 \mathrm{~m}$, com os autores justificando que o parâmetro foi fortemente influenciado pelo grande número de indivíduos de Croton sonderianus, espécie que apresentou elevada frequência no estrato entre 4,05 e 6,16m de altura.

Ao se analisar a distribuição por classe de altura, observa-se que a maior quantidade de indivíduos foi encontrada na quinta classe (6-6,9m), correspondendo acerca de $37 \%$ da população amostrada nos lotes (Figura 4), abrangendo $47 \%$, $44 \%$ e $40 \%$ dos indivíduos de $P$. pyramidalis, $P$. stipulacea e A. pyrifolium, respectivamente.

A altura média para a comunidade da área estudada foi bem superior ao obtido por Amorim et al. (2005), em uma área de Caatinga do Seridó/ $\mathrm{RN}$, encontrando a média de altura de $3,40 \mathrm{~m}$ e também ao verificado por Rodal et al. (2008), estudando a estrutura da vegetação caducifólia espinhosa de uma área do sertão central de Pernambuco, onde obtiveram a altura média de $2,37 \mathrm{~m}$, e o realizado por Santana \& Souto (2006) estudando a estrutura e diversidade fitossociológica da Caatinga na Estação Ecológica do Seridó/RN, obtendo média de altura de $2,65 \mathrm{~m}$.

Assim, baseado nessas informações, pode-se afirmar que o grau de perturbação encontrado na área de estudo, advindo da introdução da cultura do algodão, está em fase de superação, até mesmo porque existe grande preocupação dos assentados em preservar a vegetação, realizando a 


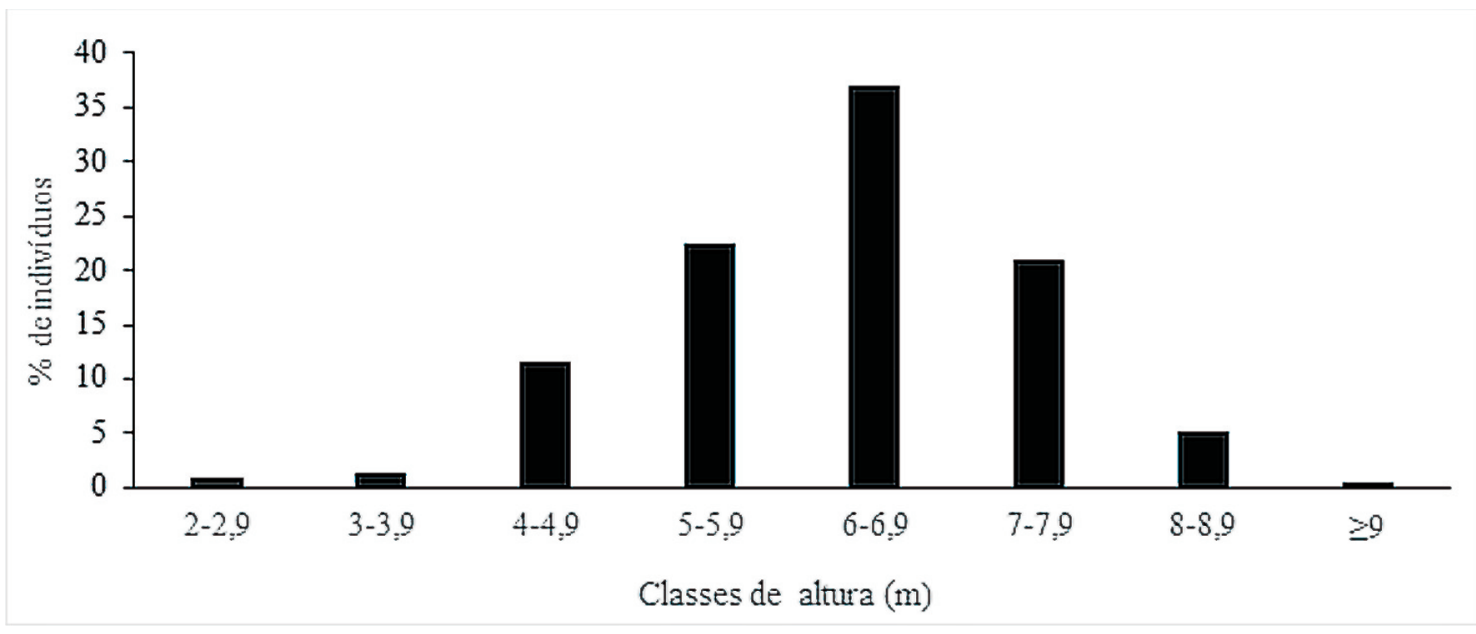

Figura 4 - Distribuição percentual dos indivíduos em classes de altura, na área dos lotes no Assentamento Rural Lagoa Nova I, Riachuelo/RN.

exploração seletiva, retirando madeira apenas das espécies identificadas pelos próprios assentados como de boa capacidade de regeneração, como M. tenuiflora, P. stipulacea e Aspidosperma pyrifolium.

\section{Conclusões}

A área dos lotes do Assentamento Rural Lagoa Nova I se encontra em bom estado de preservação da vegetação, mesmo considerando que sofreu corte raso e movimentação do solo para o plantio de algodão, estando no estágio inicial de sucessão ecológica.

A composição florística da área dos lotes é semelhante ao inventariado em outras áreas de Caatinga com condições edafoclimáticas semelhantes.

A grande diversidade observada na área estudada deve-se, em grande parte, as ações de preservação da floresta desenvolvidas pelos assentados, especialmente a proibição de corte de madeira com fins comerciais.

\section{Referências}

Alcoforado-Filho FG, Sampaio EVSB \& Rodal MJN. Florística e fitossociologia de um remanescente de vegetação caducifólia espinhosa arbórea em Caruaru, Pernambuco. Acta Botânica Brasilica, 17: 287-3030, 2003.
Alves RA, Ferreira RLC, Silva JAA, Dubeux Júnior JCB, Osajima JA \& Holanda AC. Conteúdo de nutrientes na biomassa e eficiência nutricional em espécies da Caatinga. Ciência Florestal, 27(2): 377-390, 2017.

Alves LIF, Silva MMP \& Vasconcelos KJC. Visão de comunidades rurais em Juazeirinho/PB referente à extinção da biodiversidade da Caatinga. Revista Caatinga, 21(4): 57-63, 2008.

Amorim IL, Sampaio EVSB \& Araújo EL. Flora e estrutura da vegetação arbustivo-arbórea de uma área de Caatinga do Seridó, RN, Brasil. Acta Botânica Brasilica, 19: 615-623, 2005.

Angiosperm Phylogeny Group (APG IV). An update of the Angiosperm Phylogeny Group classification for the orders and families of flowering plants: APG IV. Botanical Journal of the Linnean Society, 181(1): 1-20, 2016.

Araújo LVC. 2007. Composição florística, fitossociológica e influência dos solos na estrutura da vegetação em uma área de caatinga no semiárido paraibano. Tese (Doutorado em Agronomia). Universidade Federal da Paraíba. 121p.

Aurino ANB. 2007. Avaliação dos impactos da extração da lenha sobre a diversidade vegetal no município de Tenório, Seridó Oriental paraibano: uma perspectiva biológica e social. Dissertação (Mestrado em Desenvolvimento e Meio Ambiente). Universidade Federal da Paraíba. 100p.

Braga EP \& Cavalcante AMB. 2007. Florística e fitossociologia de um fragmento de Caatinga arbórea 
em regeneração no Ceará. In: Anais do $8^{\circ}$ Congresso de Ecologia do Brasil.

Brower JE \& Zar JH. 1984. Field and laboratory methods for general ecology. Boston, W.C. Brown Publisher. 226p.

Cabral GAL. 2014. Fitossociologia em diferentes estádios sucessionais de Caatinga, Santa TerezinhaPB. Dissertação (Mestrado em Biologia Vegetal). Universidade Federal de Pernambuco. 38p.

Calixto Júnior JT \& Drumond MA. Estudo comparativo da estrutura fitossociológica de dois fragmentos de Caatinga em níveis diferentes de conservação. Pesquisa Florestal Brasileira, 34(80): 345-355, 2014.

Camargo-Ricalde SL. Descrição, distribuição, anatomia, composição química e usos de Mimosa tenuiflora (Fabaceae-Mimosoideae) no México. Journal of Tropical Biology, 48(4): 939-954, 2000.

Carneiro CE, Alves-Araújo A, Almeida Jr. EB \& TerraAraújo MH. Sapotaceae. In: Lista de Espécies da Flora do Brasil. Jardim Botânico do Rio de Janeiro. 2015.

Climate-Data. 2016. Clima: Riachuelo (RN). Disponível em: http://pt.climate-data.org/location/880407/ Acesso em: 02 ago/2019.

Dantas IC \& Souza CMC. Arborização urbana na cidade de Campina Grande/PB: inventário e suas espécies. Revista de Biologia e Ciências da Terra, 4(2), 2004.

Dantas JG, Holanda AC, Souto LS, Japiassu A \& Holanda EM. Estrutura do componente arbustivo/ arbóreo de uma área de caatinga situada no município de Pombal/PB. Revista Verde de Agroecologia e Desenvolvimento Sustentável, 5(1): 134-142, 2010.

Embrapa-Empresa Brasileirade PesquisaAgropecuária. 2014. Solos do Nordeste. Disponível em: < http://www. uep.cnps.embrapa.br/solos/index.php > Acesso em: 22 maio 2019.

Farias RC, Lacerda AV, Gomes AC, Barbosa FM \& Dornelas CSM. Riqueza florística em uma área ciliar de Caatinga no Cariri Ocidental da Paraíba, Brasil. Revista Brasileira de Gestão Ambiental e Sustentabilidade, 4(7): 109-118, 2017.

Giulietti AM, Harley RM, Queiroz LP, Barbosa MRV, Bocage Neta AL \& Figueiredo MA. 2002. Plantas endêmicas da Caatinga, p.103-115. In: Sampaio EVSB, Giulietti AM, Virgínio J \& Gamarra-Rojas CFL (eds.). Vegetação e flora das Caatingas. APNE/CNIP.

Guedes RS. 2010. Caracterização fitossociológica da vegetação lenhosa e diversidade, abundância $e$ variação sazonal de visitantes florais em um fragmento de caatinga no semiárido paraibano. Dissertação (Mestrado em Ciências Florestais). Universidade Federal de Campina Grande. 92p.

Guedes RS, Zanella FCV, Costa Júnior JEV, Santana GM \& Silva JA. Caracterização florístico-fitossociológica do componente lenhoso de um trecho de Caatinga no semiárido paraibano. Revista Caatinga, 25(2): 99-108, 2012.

Holanda AC, Lima FTD, Silva BM, Dourado RG \& Alves AR. Estrutura da vegetação em remanescentes de caatinga com diferentes históricos de perturbação em Cajazeirinhas (PB). Revista Caatinga, 28(4): 42-150, 2015.

Jesus CG. 2010. Levantamento da vegetação arbustiva arbórea de um Fragmento de Caatinga, localizada em Castro Alves/BA. Trabalho de Conclusão de Curso (Engenharia Florestal). Universidade Federal do Recôncavo da Bahia. 48p.

Leal IR, Vicente A \& Tabarelli M. 2007. Herbivoria por caprinos na caatinga da região do Xingó: uma análise preliminar, p.695-715. In: Leal IR, Tabarelli M \& Silva JMC (eds.). Ecologia e conservação da Caatinga. Editora Universitária da UFPE. 822p.

Leitão AC, Vasconcelos WA, Cavalcante AMB, Tinôco LBM \& Fraga VS. Florística e estrutura de um ambiente transicional Caatinga - Mata Atlântica. Revista Caatinga, 27(3): 200-210, 2014.

Leite JAN, Araújo LVC, Arriel EF, Chaves LFC \& Nóbrega AMF. Análise quantitativa da vegetação lenhosa da Caatinga em Teixeira/PB. Pesquisa Florestal Brasileira, 35(82): 89-100, 2015.

Leite UT. 1999. Análise da estrutura fitossociológica do estrato arbustivo-arbóreo de duas tipologias de caatinga ocorrentes no Município de São João do Cariri/ PB. Trabalho de Conclusão de Curso (Agronomia). Universidade Federal da Paraíba. 57p.

Lima BG \& Coelho MFB. Fitossociologia e estrutura de um fragmento florestal da Caatinga, Ceará, Brasil. Ciência Florestal, 28(2): 809-819, 2018.

Machado IC \& Lopes AV. 2003. Recursos florais e sistemas de polinização e sexuais em Caatinga, p.515563. In: Leal IR, Tabarelli M \& Silva JMC (eds.). Ecologia e conservação da Caatinga. Editora Universitária da UFPE. 822p.

Magurran AE. 1988. Ecological diversity and its measurement. Princeton University Press. 197p.

Maia GN. 2004. Caatinga - árvores e arbustos e suas utilidades. 1 ed. D\&Z Computação Gráfica e Editora. 413p. 
Marangon GP, Ferreira RLC, Silva JAA, Lira DFS, Silva EA \& Loureiro GH. Estrutura e padrão espacial da vegetação em uma área de Caatinga. Floresta, 43(1): 83-92, 2013.

Martins FR. 1991. Estrutura de uma floresta mesófila. Editora da UNICAMP. 246p.

Medeiros Neto PN, Oliveira E \& Paes JB. Relações entre as características da madeira e do carvão vegetal de duas espécies da Caatinga. Floresta e Ambiente, 21(4): 484-493, 2014.

Melo JG, Amorim ELC \& Albuquerque UP. Native medicinal plants commercialized in Brazil - priorities for conservation. Environmental Monitoring Assessement, 156: 567-580, 2009.

Mendes Junior IJH, Ferreira RLC, Silva JAA, Alves Júnior FT, Silva AE \& Céspedes GHG. 2009. Distribuição espacial, diversidade florística e regeneração de uma área de Caatinga após 20 anos de corte. In: Anais da 9a Jornada de Ensino, Pesquisa e Extensão da UFRPE.

Miranda MAS. 2003. Estudo da flora herbácea de dois ambientes da FLONA - Florestal Nacional de Açú/RN. Trabalho de Conclusão de Curso (Agronomia). Escola Superior de Agricultura de Mossoró. 36p.

Nascimento SS, Lima VER \& Lima PPS. Uso do NDVI na análise temporal da degradação da Caatinga na sub-bacia do Alto Paraíba. Revista OKARA: Geografia em Debate, 8(1): 72-93, 2014.

Nunes YRF, Mendonça AVR, Botezelli L, Machado ELM \& Oliveira-Filho AT. Variações da fisionomia da comunidade arbóreos em um fragmento de floresta semidecidual em Lavras/MG. Acta Botânica Brasílica,17(2): 213-229, 2003.

Oliveira E. 2003. Características anatômicas, químicas e térmicas da madeira de três espécies de maior ocorrência no semiárido nordestino. Tese (Doutorado em Ciência Florestal). Universidade Federal de Viçosa. 122p.

Oliveira CDL, Silva APA \& Moura PAG. Distribuição e importância das Unidades de Conservação no Domínio Caatinga. Anuário do Instituto de Geociências, 42(1): 425-429, 2019.

Queiroz LP. 2009. Leguminosas da Caatinga. Universidade Estadual de Feira de Santana. 467p.

Ribeiro Filho AA, Funch LS \& Rodal MJN. Composição florística da floresta ciliar do rio Mandassaia, Parque Nacional da Chapada Diamantina, Bahia, Brasil. Rodriguésia, 60(2): 265-276, 2009.
Rodal MJN, Martins FR \& Sampaio EVSB. Levantamento quantitativo das plantas lenhosas em trechos de vegetação de Caatinga em Pernambuco. Revista Caatinga, 21(3): 192-205, 2008.

Sá IB, Cunha TJF, Teixeira AHC, Angeloti F \& Drumond MA. Processos de desertificação no Semiárido brasileiro. p.126-158, cap. IV. In: Sá IB \& Silva PCG (eds.). Semiárido brasileiro: pesquisa, desenvolvimento e inovação. Petrolina: Embrapa Semiárido, 2010.

Sabino FGS, Cunha MCL \& Santana GM. Estrutura da vegetação em dois fragmentos de Caatinga antropizada na Paraíba. Floresta e Ambiente, 23(4): 487-497, 2016.

Santana JAS. 2005. Estrutura fitossociológica, produção de serapilheira e ciclagem de nutrientes em uma área de Caatinga no Seridó do Rio Grande do Norte. Tese (Doutorado em Agronomia). Universidade Federal da Paraíba. 206p.

Santana JAS \& Souto JS. Diversidade e estrutura fitossociológica da Caatinga na Estação Ecológica do Seridó/RN. Revista de Biologia e Ciências da Terra, 6(2): 232-242, 2006.

Santana JAS, Pimenta AS, Souto JS, Vieira FA \& Pacheco MV. Levantamento florístico e associação de espécies na Caatinga da Estação Ecológica do Seridó, Serra Negra do Norte/RN, Brasil. Revista Verde de Agroecologia e Desenvolvimento Sustentável, 4(4): 8389, 2009.

Santos RM, Barbosa ACMC, Almeida HS, Vieira FA, Santos PF, Carvalho DA \& Oliveira Filho AT. Estrutura e florística de um remanescente de Caatinga arbórea em Juvenília, Norte de Minas Gerais, Brasil. Revista Cerne, 17(2): 247-258, 2011.

Santos WS, Souza MP, Nóbrega GFQ, Medeiros FS, Alves AR \& Holanda AC. Caracterização florísticofitossociológica do componente lenhoso em fragmento de Caatinga no município de Upanema/RN. Nativa, 5(2): 85-91, 2017.

Scipioni MC, Galvão F \& Longhi SJ. Composição florística e estratégias de dispersão e regeneração de grupos florísticos em Florestas Estacionais Deciduais no Rio Grande do Sul. Floresta, 43(2): 241-254, 2013.

Silva SO. 2009. Estudo de duas áreas de vegetação da Caatinga com diferentes históricos de uso no Agreste pernambucano. Dissertação (Mestrado em Ciências Florestais). Universidade Federal Rural de Pernambuco. 83p.

Tabarelli M, Silva JMC, Santos AM \& Vicente A. 2000. Análise de representatividade das unidades de 
conservação de uso direto e indireto na Caatinga: análise preliminar, p.13. In: Anais do Workshop Avaliação e identificação de ações prioritárias para a conservação, utilização sustentável e repartição de benefícios da biodiversidade do bioma Caatinga. 404p.
Taylor N. 1997. Cactaceae, p.17-20. In: Oldfield S (ed.). Cactus and succulent plants: status survey and conservation action plan. International Union of Conservation of Nature. 226p.

\section{Biodiversidade Brasileira - BioBrasil. \\ Fluxo Contínuo}

n. 1,2021

http://www.icmbio.gov.br/revistaeletronica/index.php/BioBR

Biodiversidade Brasileira é uma publicação eletrônica científica do Instituto Chico Mendes de

Conservação da Biodiversidade (ICMBio) que tem como objetivo fomentar a discussão $e$ a disseminação de experiências em conservação e manejo, com foco em unidades de conservação $e$ espécies ameaçadas.

ISSN: 2236-2886 